\title{
Faktor-Faktor Yang Mempengaruhi Kepatuhan Dokter Dalam Mengisi Rekam Medis Di Unit Rawat Inap Rumah Sakit Wava Husada
}

\author{
Doby Irawan ${ }^{1}$ \\ ${ }^{1}$ Program Magister Manajemen Rumah Sakit Universitas Brawijaya/Program Studi \\ Pendidikan Dokter Fakultas Kedokteran dan Ilmu-Ilmu Kesehatan \\ Universitas Islam Negeri Maulana Malik Ibrahim Malang \\ Email : dobynia@gmail.com
}

\begin{abstract}
ABSTRAK
Rumah sakit sebagai organisasi publik yang terdiri dari beberapa tenaga dengan berbagai disiplin ilmu, diharapkan mampu memberikan pelayanan kesehatan yang bermutu kepada masyarakat. Layanan kesehatan yang bermutu harus mampu memberikan informasi yang jelas tentang apa, siapa, kapan, di mana, dan bagaimana layanan kesehatan itu akan atau telah dilakukan dalam bentuk rekam medis yang dapat dipertanggungjawabkan oleh dokter dan tenaga kesehatan lainnya.Studi dilakukan dengan metode survey selama 3 minggu pada 26 responden (dokter umum dan spesialis) yang melakukan pelayanan di rawat inap Rumah Sakit Wava Husada Kepanjen. Teknik penggalian data menggunakan kuesioner. Metode analisa data dengan brainstorming dan Literature review.26 kuesioner terisi lengkap; terdapat karakteristik dokter menurut umur; 30\% berumur 25-34 tahun, 25\% berumur 35-44 tahun, $25 \%$ berumur $45-54$ tahun dan $20 \%$ berumur 55-64 tahun.Menurut jenis kelamin; $80 \%$ pria dan $20 \%$ wanita. Menurut kompetensinya $20 \%$ dokter umum dan $80 \%$ dokter spesialis. Menurut lama kerja di Rumah Sakit Wava Husada; $48 \%$ responden bekerja selama 0-5 tahun dan 52\% responden sudah bekerja selama 6-10 tahun. Aspek sikap dokter ditemukan dokter sering terburu-buru (40\%), tidak bersedia meluangkan waktu (5\%) dan pernah mengingatkan teman sejawat untuk melengkapi rekam medis (20\%). Aspek form rekam medis, dokter masih menganggap susunan form rekam medis masih belum sesuai (15\%). Aspek Rumah Sakit; sebagian dokter merasa tempat kerja belum nyaman (15\%), belum mendapatkan umpan balik (10\%) dan himbauan untuk melengkapi rekam medis (20\%). Dalam survey juga ditemukan keinginan-keinginan para dokter agar rekam medis dapat terisi lengkap sesuai Standar Pelayanan Minimal.Kelengkapan rekam medis dipengaruhi oleh sikap dokter, form rekam medis serta tenaga rekam medis sebagai penyelenggara layanan rekam medis di Rumah Sakit. Diperlukan kolaborasi dan sinergi antara tenaga rekam medis, perawat dan dokter dalam upaya meningkatkan angka kelengkapan rekam medis.
\end{abstract}

Kata kunci :Form rekam medis, perawat, dokter, kolaborasi dan sinergi. 


\begin{abstract}
The hospital is a public organization that consists of several person with their scientific competences, that is hoped to give a qualified health service to the people. The qualified health service has to be able to give clear information about what, who, when, where and how the health service will be done or had done in form of eligible medical record by the doctors and other medical persons. The study was done by survey method for three weeks on 26 respondents (general doctors and specialist) who give health service in Wava Husada Hospital Care Unit, Kepanjen. The data collecting technique is using questionaires. The data analysis methods with brainstorming and Literature Review.26 questionaires were fulfilled completely; there are doctor's character according to age, $30 \%$ is between $25-34$ years old, $25 \%$ is 45 54 years old and 20\% is 55-64 years old. According to the gender, there are $80 \%$ men and $20 \%$ women. According to their competences, $20 \%$ general doctors and $80 \%$ are specialists. According to the work experience in Wava Husada Hospital, there are $48 \%$ respondent have worked for $0-5$ years, $52 \%$ have worked for 6-10 years. The attitude aspects of doctor is founded to be in hurry (40\%), unwilling to give their time $(5 \%)$ and have ever reminded their colleague to fulfill the medical record (20\%). The medical record form aspects, the doctors still thinks that the medical record for is not appropriate $(15 \%)$, several doctors thinks that the working place is not comfortable (15\%), have not been given feedbacks (10\%) and the order to fulfll the medical report (20\%). There are also found during the survey, several willings of the doctors about the medical record to be fulfilled completely according to Minimum Service Standard.Completing medical record is affected by the doctors' attitude towards the records, the form of the medical record and the medical record person as the service agent of medical record in the hospital. It is needed a good collaboration and synergy between the medical record person, the nurses and the doctors in order to increase the medical records completing number.
\end{abstract}

Keywords : Medical Report Forms, Nurses, Doctors, Collaborations and synergy 


\section{PENDAHULUAN}

Rumah sakit sebagai organisasi publik yang terdiri dari beberapa tenaga dengan berbagai disiplin ilmu, diharapkan mampu memberikan pelayanan kesehatan yang bermutu kepada masyarakat. Mutu pelayanan merupakan suatu hal yang sangat penting untuk tetap dapat menjaga keberadaan suatu rumah sakit [1]. Layanan kesehatan yang bermutu harus mampu memberikan informasi yang jelas tentang apa, siapa, kapan, di mana, dan bagaimana layanan kesehatan itu akan atau telah dilakukanRekam medik dipergunakan sebagai bukti tertulis yang dapat dipertanggungjawabkan oleh dokter dan tenaga kesehatan lainnya [3]. Maka dari itu, rekam medis merupakan salah satu bagian penting dalam pelayanan kesehatan di rumah sakit [4]. Hal ini mengingat rekam medis merupakan salah satu standar yang harus dipenuhi oleh rumah sakit untuk mendapatkan predikat akreditasi [5].

Rekam medis disebut lengkap apabila rekam medis tersebut telah berisi seluruh informasi tentang pasien termasuk resume medis, keperawatan dan seluruh hasil pemeriksaan penunjang serta telah diparaf oleh dokter yang bertanggung jawab. Berdasarkan Keputusan Menteri Kesehatan Republik Indonesia Nomor: 129/Menkes/SK/II/2008 tentang Standar Pelayanan Minimal Rumah Sakit menyatakan bahwa pada jenis pelayanan rekam medis, indikator kelengkapan pengisian rekam medis $1 \times 24$ jam setelah selesai pelayanan dengan standar kelengkapan pengisian rekam medis $100 \%$ [6].

Wava Husada adalah salah satu Rumah Sakit di Kepanjen yang berdiri sejak januari 2006 merupakan rumah sakit swasta yang terakterditasi penuh setingkat rumah sakit tipe C. Rumah sakit yang memiliki luas lahan $14.876 \mathrm{~m} 2$, luas bangunan $7.505 \mathrm{~m} 2$ dengan kapasitas 154 TT dan juga jumlah karyawan yang besar bisa berpotensi terjadinya masalah di Unit Rekam Medis.

Pada studi pendahuluan dilakukan identifikasi masalah dengan cara mengumpulkan data dasar Rumah Sakit Wava Husada berdasarkan penerapan visi, misi, tujuan, sasaran, sumber daya manusia yang dimiliki, hasil pencapaian kinerja baik tingkat 
efektivitas, efisiensi dan kinerja tiap unitnya didapatkan 10 prioritas masalah yang ada kemudian diajukan kepada pembimbing lapangan untuk dilakukan brainstorming dan FGD dengan seluruh kepala bidang dan direktur Rumah Sakit Wava Husada. Sehingga disepakati satu masalah yang akan diangkat sebagai tema magang yaitu "faktor-faktor apa saja yang mempengaruhi kepatuhan dokter dalam mengisi rekam medis di unit rawat inap Rumah Sakit Wava Husada". Berdasarkan hasil studi pendahuluan dengan observasi dan wawancara ditemukan angka kelengkapan pengisian rekam medis hanya 90\% belum sesuai dengan Standar Pelayanan Minimal [7].

\section{METODE}

Studi ini dimulai dengan identifikasi akar masalah dilakukan dengan mengajukan pertanyaan "mengapa" (5 Why) berulang-ulang sampai jawabannya tidak dapat ditemukan lagi. Pada saat pertanyaan "mengapa" tidak dapat dijawab lagi berarti akar masalah sudah ditemukan. Akar masalah juga dapat ditelusuri dengan diagram fishbone.Setelah menemukan akar masalah yaitu pengisian rekam medis oleh dokter yang masih rendah. Untuk menilai kepatuhan dalam mengisi kelengkapan rekam medis dilaksanakan dengan mensurvey sikap para dokter dengan metode kuisioner. Kuesioner menggunakan pertanyaan tertutup dengan 3Skala Likert (modifikasi dari 5 Skala Likert) untuk menilai sikap dokter, form rekam medis dan rumah sakit. Kuesioner juga dilengkapi dengan pertanyaan terbuka untuk mengungkapkan informasi tentangapa yang diinginkan dokter agar form rekam medis bisa terisi lengkap. Sampel diambil dari jumlah populasi yaitu semua dokter yang melayani pasien rawat inap.Hasil observasi dan kuisioner diolah dan dilakukan brainstorming dengan manajemen rumah sakit. Kemudian disusun analisis perilaku dokter terhadap kepatuhan pengisian kelengkapan rekam medis [12] 


\section{HASIL}

Survey dilakukan selama 3 minggu, dimulai dari tanggal 29 September sampai dengan 20 Oktober 2014 terhadap 26 dokter (umum dan spesialis) yang melakukan pelayanan rawat inap di Rumah Sakit Wava Husada. Terdapat hasil 26 kuesioner terisi lengkap, sebaran responden (tabel 1) menurut umur, yaitu : 30\% berumur 25-34 tahun, 25\% berumur 35-44 tahun, 25\% berumur $45-54$ tahun dan 20\% berumur 55-64 tahun. Dari 26 responden diketahui $80 \%$ pria dan $20 \%$ wanita. Kompetensinya $20 \%$ dokter umum dan $80 \%$ dokter spesialis. Sebaran responden berdasarkan lama kerja di Rumah Sakit Wava Husada, yaitu : 48\% responden bekerja selama 0-5 tahun dan $52 \%$ responden sudah bekerja selama 6-10 tahun.

Tabel 1.Karakteristik Responden Dokter Umum dan Spesialis

\begin{tabular}{lc}
\hline \multicolumn{1}{c}{ Karakteristik } & Responden $(\mathbf{N}=\mathbf{2 6})$ \\
\hline Umur & \\
$25-34$ & 30 \\
$35-44$ & 25 \\
$45-54$ & 25 \\
$55-64$ & 20 \\
Jenis Kelamin & \\
Pria & 80 \\
Wanita & 20 \\
Kompetensi & \\
Dokter Umum & 20 \\
Dokter Spesialis & 80 \\
Lama kerja (tahun) & \\
0 s/d 5 & 46 \\
6 sd 10 & 54 \\
\hline
\end{tabular}

Keterangan : N (responden)

Hasil survey menunjukan bahwa sikap para dokter terhadap kepatuhan dalam melengkapi rekam medis dipengaruhi oleh waktu yang dimiliki dokter dan adanya kolaborasi antara para dokter dengan paramedis dalam melengkapi rekam medis (Tabel 2). Terdapat 95\% dokter merasa bertanggung jawab untuk melengkapi rekam medis, $90 \%$ dokter bersedia meluangkan waktunya untuk melengkapi rekam medis 
dan 95\% melakukannya setelah pemeriksaan pasien selesai, 95\% dokter ingin dingatkan oleh paramedis untuk melengkapi rekam medis. Sebanyak $40 \%$ dokter merasa terburu-buru dalam mengisi form rekam medis ini disebabkan banyaknya jumlah dan tempat praktek dokter. 55\% doktermempunyai pandangan bahwa pengisian rekam medis adalah kewajiban setiap dokter sehingga tidak perlu saling mengingatkan dalam melengkapi rekam medis.

Tabel 2. Sikap Dokter Dalam Melengkapi Rekam Medis

\begin{tabular}{clccc}
\hline NO & \multicolumn{1}{c}{ SIKAP } & TS & R & S \\
\hline 1 & Saya bertanggung jawab untuk melengkapi pengisian & & $5 \%$ & $95 \%$ \\
2 & rekam medis & $5 \%$ & $5 \%$ & $90 \%$ \\
3 & Saya bersedia meluangkan waktu untuk melengkapi & & $5 \%$ & $95 \%$ \\
4 & rekam medis & $5 \%$ & $95 \%$ \\
5 & Saya ingin diingatkan oleh paramedis agar melengkapi & $35 \%$ & $25 \%$ & $40 \%$ \\
6 & form rekam medis. & $55 \%$ & $25 \%$ & $20 \%$
\end{tabular}

Saya mengisi form rekam medis setelah pemeriksaan pasien selesai.

Saya sering terburu-buru dalam mengisi form rekam medis.

Saya pernah mengingatkan teman sejawat untuk melengkapi rekam medis.

Keterangan : TS (tidak setuju), R (ragu-ragu) dan S (setuju)

Para dokter sebanyak 95\% menginginkan agar form rekam medis diberi warna atau tanda khusus agar mudah dikenali (Tabel 3). 70\% dokter menilai bahwa rekam medis di rumah sakit wava husada sudah sesuai/berurutan dan $85 \%$ dokter menilai pengisian rekam medis lebih mudah dan sederhana dibandingkan rumah sakit yang lain.

Tabel 3.Peran Form Dalam Kelengkapan Rekam Medis

\begin{tabular}{|c|c|c|c|c|}
\hline NO & FORM REKAM MEDIS & TS & $\mathbf{R}$ & $\mathbf{S}$ \\
\hline 1 & $\begin{array}{l}\text { Menurut saya, rekam medis merupakan dokumen } \\
\text { rahasia dan sangat penting }\end{array}$ & & & $100 \%$ \\
\hline 2 & $\begin{array}{l}\text { Saya menilai susunan lembar form rekam medis di } \\
\text { Rumah Sakit Wava Husada sudah berurutan/sesuai. }\end{array}$ & $15 \%$ & $15 \%$ & $70 \%$ \\
\hline 3 & $\begin{array}{l}\text { Saya ingin lembar form rekam medis untuk dokter } \\
\text { diberi warna/tanda khusus agar mudah dikenali. }\end{array}$ & & $5 \%$ & $95 \%$ \\
\hline 4 & Dibandingkan dengan RS lain, pengisian rekam medis & & & \\
\hline
\end{tabular}


di Rumah Sakit Wava Husada lebih mudah dan sederhana

$15 \% \quad 85 \%$

Keterangan : TS (tidak setuju), R (ragu-ragu) dan S (setuju)

Rumah Sakit Wava Husada sudah berupaya agar rekam medis dapat terisi dengan lengkap (Tabel 4), seperti selalu melakukan evaluasi kelengkapan pengisian rekam medis, memberikan peringatan berupa teguran kepada dokter yang belum lengkap pengisian rekam medis pasien yang dirawatnya serta menyediakan fasilitas yang nyaman untuk dokter.

Tabel 4. Peran Rumah Sakit Dalam Kelengkapan Rekam Media

\begin{tabular}{clccc}
\hline NO & RUMAH SAKIT WAVA HUSADA & TS & R & S \\
\hline 1 & $\begin{array}{l}\text { Pihak RS Wava Husada selalu melakukan evaluasi } \\
\text { kelengkapan pengisisan rekam medis dan memberikan }\end{array}$ & $10 \%$ & $15 \%$ & $75 \%$ \\
2 & $\begin{array}{l}\text { umpan baliknya kepada saya } \\
\text { Pihak RS Wava Husada sudah memberikan himbauan } \\
\text { kepada saya, karena terlambat melengkapi rekam medis } \\
\text { Tempat kerja saya untuk melengkapi pengisian rekam } \\
\text { medis cukup nyaman }\end{array}$ & $15 \%$ & $20 \%$ & $60 \%$ \\
\hline Keterangan : TS (tidak setuju), R (ragu-ragu) dan S (setuju) & & $60 \%$ \\
\end{tabular}

Pada kuisioner terdapat pertanyaan terbuka dimana hampir seluruh dokter yang merawat pasien di Rumah Sakit Wava Husada memberikan pernyataan dan saran (Tabel 5).Pernyataan dan saran ini merupakan gambaran keinginan para dokter dalam melengkapi rekam medis, hal ini dapat dijadikan tolak ukur atau panduan bagi manajemen rumah sakit untuk membuat kebijakan agar pengisian rekam medis bisa mendekati 100\% sesuai dengan target Standar Pelayanan Minimal. 
Tabel 5. Faktor-faktor yang Diinginkan Dokter Agar Rekam Medis Bisa Terisi

Lengkap

\begin{tabular}{cl}
\hline NO & \multicolumn{1}{c}{ KEINGINAN PARA DOKTER } \\
\hline 1 & Memberikan kesempatan kepada DPJP untuk mengisi rekam medis dalam \\
& waktu 2x24 jam dari pasien pulang di rawat inap \\
2 & Reminding DPJP dari ruang perawatan \\
3 & Reward bagi dokter yang rekam medisnya terisi lengkap \\
4 & Form lebih praktis dan mudah \\
5 & Peran aktif paramedis untuk mengingatkan DPJP \\
6 & Koreksi rekam medis harus setip hari jangan ditumpuk tiap bulan \\
7 & Perlu gambar anatomi untuk status UGD \\
8 & Disediakan buku ICD 9/10 \\
9 & Disiapkan komputer di OK untuk trial tindakan (BPJS) \\
10 & Kolaborasi dengan paramedis dalam membantu kelengkapan rekam medis \\
11 & Form rekam medis dibedakan antara pasien trauma dan non trauma \\
12 & Form rekam medis diberikan lebih cepat \\
13 & Form rekam medis penyakit mata diberi warna yang berbeda dengan spesialis \\
14 & lain \\
15 & Ada gambar anatomi di form rekam medis dimasing-masing bidang \\
16 & Form pemeriksaan penunjang dipisahkan (warna/tanda khusus) \\
17 & Form resume lebih lengkap lagi \\
& Untuk pasien asuransi, rekam medis sebaiknya lebih sederhana (tidak banyak \\
& menulis hal yg sama) \\
\hline
\end{tabular}

\section{PEMBAHASAN}

Dalam studi ini ditemukan bahwa kelengkapan rekam medis dipengaruhi oleh beberapa faktor seperti sikap dokter, form rekam medis itu sendiri dan tenaga rekam medis. Dari studi-studi terdahulu dikemukakan beberapa faktor yang dapat mempengaruhi kepatuhan dokter dalam melengkapi rekam medis. Elynar Lubis mengatakan dalam studinya bahwa karakteristik individu dan motivasi mempengaruhi kinerja dokter dalam kelengkapan pengisian rekam medis [1]. Karakteristik individu meliputi usia, jenis kelamin, tingkat pendidikan dan lamakerja, 
sedangkan variabel motivasi meliputi kompensasi, kondisi kerja,status kepegawaian, prosedur, dan supervisi. Dari hasil survey, ditemukan bahwasebaran responden berumur 25-34 tahun (30\%), 35-44 tahun (25\%), 45-54 tahun (25\%) dan berumur 5564 tahun (20\%).Andrew McGhie mengemukakan bahwa semakin tua umur seseorangakan mengalami perubahan kepribadian yang berkaitan dengan usia yangsebenarnya, yang merupakan reaksi terhadap sikap masyarakat [8].Sehinggabisa disimpulkan dokter yang semakin tua mempunyai kematangan,bertanggung jawab dan lebih teliti dalam melaksanakan tugas-tugas sebagaidokter termasuk dalam melakukan pengisian data rekam medis pasien padalembar resume pasien rawat inap. Komposisi pria lebih banyak (80\%) dibandingkan dengan wanita (20\%). MenurutRuth Tiffani Bamhouse menyatakan tidak ada perbedaan bawaan antara priadan wanita, sedangkan pendapat Wasti Soemanto yang membedakan antaralaki laki dan perempuan adalah dalam hal peranan dan perhatian terhadapsesuatu pekerjaan dan inipun merupakan akibat dari pengaruh kultural, halini bisa diartikan bahwa tidak ada perbedaan tanggung jawab dan bebankerja antara pria dan wanita. Sehingga disimpulkan antara jenis kelaminlaki-laki dan perempuan mempunyai tanggung jawab yang sama dalampengisian data rekam medis pasien pada lembar resume rawat inap.

Kompetensi dokter umum (20\%) dan dokter spesialis (80\%).Irmawaty Indar menemukan dalam studinya bahwa baik dokter umum maupun dokter spesialis mempunyai persentase kelengkapan pengisian rekam medis yang tidak lengkap yang keduanya tinggi bila dibandingkan dengan yang lengkap. Hal ini juga menunjukkan bahwa tingkat pendidikan dokter pada penelitian ini tidak mempengaruhi kelengkapan pengisian rekam medis [9]. Namun hasil ini bertentangan dengan penelitian oleh Sugiyanto tentang analisis perilaku dokter dalam mengisi kelengkapan data rekam medis lembar resume rawat inap di Rumah Sakit Ungaran yang menyimpulkan adanya hubungan antara pengetahuan dan pengetahuan, jabatan struktural dan tugas utama dokter. Dimana antara dokter umum dan dokter spesialis terdapat perbedaan tingkat pengetahuan dan tugas utama dokter [10]. 
Sebaran responden berdasarkan lama kerja di Rumah Sakit Wava Husada, yaitu : bekerja selama 0-5 tahun (48\%) dan responden sudah bekerja selama 6-10 tahun (52\%).Azizah mengatakanmasa kerja yang sudah lama umumnya mempunyai tingkat kejenuhan yang tinggi yang berhubungan dengan keadaan kerja. Banyaknya perkembangan terbaru yang berhubungan dengan rekam medis baik sarana, aturan maupun kebijakan-kebijakan lainnya sangat berpengaruh pada kelengkapan pengisian rekam medis. Hal ini juga menunjukkan bahwa masa kerja yang lama berhubungan dengan kelengkapan pengisian rekam medis.Hal ini juga sesuai pernyataan sugiyanto bahwa dengan berkembangnya evidence based medicine dimana pelayanan medis yang berbasis data sangatlah diperlukan maka data dan informasi pelayanan medis yang berkualitas terintegrasi dengan baik dan benar sumber utamanya adalah data klinis dari rekam medis. Data klinis yang bersumber dari rekam medis semakin penting dengan berkembangnya rekam medis elektronik, dimana setiap entry data secara langsung menjadi masukan (input) dari sistem/manajemen informasi kesehatan [10].

Yuliana Leli mengatakan salah satu penyebab ketidaklengkapan pengisian rekam medis karenaketidakterisian diagnosis akhir (74\%).Ketidaklengkapan tersebut dikarenakan :kesibukan dokter,keterbatasan waktu dokter, form resume tersusun diurutan paling belakang dan belum adanyaprotap baku pengisian rekam medis [11]. Hal ini sejalan dengan hasil survey terhadap sikap dokter, dimana dokter sering terburu-buru dalam mengisi form rekam medis (40\%) dan tidak bersedia meluangkan waktunya untuk melengkapi rekam medis (5\%) dikarenakan kesibukan dan banyaknya tempat praktek.

Izha Sukma R, dkk mengatakan ketidaklengkapan rekam medis dipengaruhi 2 aspek yaitu aspek sumber daya manusia dan aspek prosedur pelaksanaan [12]. Pada aspek sumber daya manusia didapatkan bahwa tingkat kedisiplinan dokter dan perawat sangat kurang dalam pengisian dokumen rekam medis, sumber daya manusia yang terbatas mempengaruhi kecepatan dalam pengembalian dokumen rekam medis yang tidak lengkap. Untuk aspek prosedur pelaksanaan ditemukan prosedur tetap 
pengelolaan dokumen rekam medis yang belum dijalankan secara optimal sehingga dokumen rekam medis yang tidak lengkap harus dikembalikan dalam batas waktu 2x24 jam. Hal ini sejalan dengan keinginan sebagian dokter di Rumah Sakit Wava Husada agar diberi waktu pengisian rekam medis selama 2x24 jam, namun hal ini bertentangan dengan Permenkes no. 269 tahun 2008 Bab III ayat 2 tentang Tata Cara Penyelenggaraan rekam medis dan Standar Pelayanan Minimal [4].

Menurut manual rekam medis yang diterbitkan oleh konsil kedokteran Indonesia, rekam medis untuk rawat inap sekurang-kurangnya memuat: identitas pasien, pemeriksaan, diagnosis/masalah, persetujuan tindakan medis (bila ada), tindakan/pengobatan, pelayanan lain yang telah diberikan kepada pasien. Dalam mengisian rekam medis selain dokter/dokter gigi juga bisa dilakukan oleh tenaga kesehatan lainnya dengan cara pendelegasian oleh dokter yang merawat secara tertulis kepada tenaga kesehatan yang memberikan pelayanan langsung kepada pasien seperti yang tertuang dalam manual rekam medis yang disusun oleh Konsil Kedokteran Indonesia [13].

\section{KESIMPULAN}

Kelengkapan rekam medis dipengaruhi oleh sikap dokter, form rekam medis serta tenaga rekam medis sebagai penyelenggara layanan rekam medis rumah sakit. Berdasarkan hasil telusur di unit rekam medis, pada sampel rekam medis bulan agustus 2014 didapatkan hampir seluruh rekam medis tidak lengkap (90\%). Hal ini menunjukan rendahnya kewajiban, kedisiplinan dan kepedulian dokter terhadap kelengkapan rekam medis. Kolaborasi antara tenaga rekam medis, perawat dan dokter yang merawat sangat diperlukan agar rekam medis bisa terisi lengkap. Sarannya, 1. Manajemen Rumah Sakit Wava Husada membuat SOP yang bakudan mensosialisasikannya agar dapat berjalan dengan baik dan berkesinambungan.2. Memfasilitasi keinginan dokter tentang kenyamanan, kolaborasi perawat dengan dokter dalam bentuk saling mengingatkan dan modifikasi form rekam medis agar mudah dilengkapi. 


\section{DAFTAR PUSTAKA}

1. Lubis E. Pengaruh Karakteristik Individu dan Motivasi Ekstrinsik terhadap Kinerja Dokter dalam Kelengkapan Pengisian Rekam Medis Pasien Rawat Inap di Rumah Sakit PT Perkebunan Nusantara IV (Persero) 2009.

2. Pohan SI. Dasar-dasar Pengertian dan Penerapan. Jakarta: EGC; 2007.

3. Djojodibroto D. Kiat Mengelola Rumah Sakit. Jakarta: Hipokrates; 1997.

4. Kemenkes. Nomor 269/MENKES/PER/III/2008 tentang Rekam Medis. 2008.

5. Departemen Kesehatan Republik Indonesia Direktorat Jendral Pelayanan Medik. Pedoman Pengelolaan Rekam Medis: Jakarta; 1998.

6. Kemenkes. Nomor: 129/Menkes/SK/II/2008 tentang Standar Pelayanan Minimal Rumah Sakit 2008.

7. Rumah Sakit Wava Husada Kepanjen. Laporan Tahunan 2013.

8. Andrew McGhie. Psychology as Applied to Nursing. Yogyakarta: Andi Offset; 1996.

9. Indar I, Naiem MF. Faktor yang berhubungan dengan kelengkapan rekam medis di RSUD H. Padjonga Ngalle Takalar. Jurnal Adminsitrasi \& Kebijakan Kesehatan Indonesia. 2013;2(02).

10. Sugiyanto Z. Analisis perilaku dokter dalam pengisian kelengkapan rekam medis lembar resume rawat inap di RS Ungaran. Ilmu Kesehatan Masyarakat. 2005.

11. Yuliana L. Upaya Menyelesaikan Masalah Ketidakterisian Diagnosis Akhir pada Lembar Ringkasan Masuk dan Keluar di Rumah Sakit Panti Rini Kalasan Yogyakarta 2010.

12. Izha Sukma Rahmadhani SS, Antik Pujihastuti,. Faktor Penyebab Ketidaklengkapan Dokumen Rekam Medis Pasien Rawat Inap Dalam Batas Waktu Pelengkapan Di Rumah Sakit Umum Daerah Dr. Moewardi Surakarta. Jurnal Kesehatan. 2008;II(2):82-8.

13. Konsil Kedokteran Indonesia. Manual rekam medis 2006. 